\title{
Fugas e reescravizações em região fronteiriça - Bolívia e Brasil nas primeiras décadas dos Estados nacionais
}

\author{
Fugues and "reenslavement" in the border \\ region - Bolivia and Brazil in the first decades \\ of national States
}

Ernesto Cerveira de Sena*

Resumo: Com o início dos Estados nacionais na América, era contingente que se estabelecessem limites territoriais, tal como Bolívia e Brasil. Antes disso, aporias como a fuga de escravos eram motivos de estratégias e ações várias. Autoridades locais procuravam defender os interesses dos proprietários. A Bolívia, controversamente, se apresentava "como solo livre" da escravidão, mas mantinha em seu território escravos negros, além de seus habitantes cederem às recompensas de capturas de fugidos.

Palavras-chave: Fronteira. Escravos. Estados nacionais.

Abstract: With the beginning of National States in America, it was contingent that territorial boundaries were estabilished, such as Bolivia and Brazil. Before that, issues such as the slaves escape were reasons for many actions and strategies. Local officials sought to defend the interests of their owners. In the other hand, Bolivia, controversially, was presented as "free soil" of slavery but kept black slaves in its territory, and its inhabitants ceded to rewards to catch the escapees.

Keywords: Boundary. Slaves. National States.

* Professor da Graduação, de História da América, e do Programa de Pós-Graduação em História da Universidade Federal de Mato Grosso. Doutor em História pela Universidade de Brasília. Faz estágio pós-doutoral na Universidade Federal Fluminense. <ernesto. sena@gmail.com>. Seção de artigos do Periódico. Pesquisa parcialmente financiada pelo CNPq. 
O século XIX foi o tempo da formação dos Estados nacionais. Para Benedict Anderson, autor de Comunidades imaginadas, o livro possivelmente mais referenciado em textos sobre nações modernas, seria na América onde se daria primeiro esse tipo de formação de coletividade, ligada a uma ideia de comunidade imaginária, atrelada a certo desenvolvimento do capitalismo, estrutura burocrática, prescindindo das formas étnicas elementares como fundamento aglutinador, pelo menos em um primeiro momento, ao contrário do que acontecia na Europa. Assim, seriam as nações criollas as pioneira (Anderson, 2008 [1989])1 ${ }^{1}$. Por outro lado, para François-Xavier Guerra, foram nas grandes monarquias católicas, Espanha e França, que se engendrou a ideia de nação moderna, por isso foram unificados vários rincões, sendo umbilicalmente ligados a um Estado ativo, sem deixarem de ser vinculados a tradições ou costumes que procurariam amalgamar as várias e díspares regiões e populações (Guerra, 2003).

Em uma coletânea sobre o estado da arte das pesquisas e reflexões sobre nações, sobretudo as modernas, publicada posteriormente à primeira edição do livro marcante de Benedict Anderson, o mesmo autor, a quem coube a introdução da obra, reconhece que ainda não há uma definição e uma historicidade unívoca e suficiente que possa descrever e conceitualizar as nações concebidas hodiernamente (Anderson, in: Balakrishnan, 2000). No entanto, parece não haver dúvida de que foi em fins do século XVIII, mas sobretudo no século XIX, o momento em que no Ocidente foi criada e reforçada a ideia de "nação moderna", transformando pensamentos políticos e concepções de relacionamento entre e dentro das populações de um mesmo território. Se algumas pesquisas apontam os muitos significados da palavra "nação" e "pátria" ainda no Antigo Regime ocidental, a nação teria outro significado desde fins do século XVIII (Kidd, 2006), sendo reforçada a percepção política e a tentativa unificadora no século XIX, mesmo preservando as diferenças sociais internas dentro de uma mesma terra nacional.

Seguindo as ideias de Guerra, a soberania, antes residente na figura do rei com vassalagem em territórios descontínuos, em vários continentes, passou a residir, em tese, no seu "povo", que habitava determinada área geográfica. $\mathrm{O}$ território também passou a ser símbolo da nova soberania (Guerra, 2003, p. 40-41). Pela nova nação dever-se-ia matar e morrer, como aludiu Anderson (2008, p. 81-86) ${ }^{2}$. Não mais

A primeira edição desse texto foi publicada em 1989, pela editora Ática.

2 Quem estaria disposto a morrer pela Comunidade Econômica Europeia? O autor exemplifica para mostrar o sentido de "comunidade imaginada". 
em nome do monarca, mas em nome do novo país que se construía, indicando uma novidade política no subcontinente, mesmo que apoiada em "antigas prerrogativas", como foi o caso do reciclado Direito das Gentes (ou Natural), que seria usado como argumento para a não aceitação da autoridade monárquica, tida como opressiva no Novo Mundo hispânico (Chiaramonte, 2004).

Com as independências, elites dirigentes passaram a reivindicar territórios que deveriam corresponder à espacialidade dos novos países que surgiam. No caso da América espanhola, não houve uma "fragmentação" dos territórios, pois não existia uma continuidade idêntica e inquestionável entre o que eram os vice-reinados e governadorias com as novas repúblicas, o que causaria muitas controvérsias posteriores, inclusive com a vizinhança brasileira. Os vários países que surgiram não seguiram nenhuma lógica inequívoca que corresponderia precisamente ao que seriam as novas unidades políticas.

No Império do Brasil, no momento da independência, existia um mosaico de entidades políticas que não necessariamente indicaria um único território chamado Brasil (Jancsó; Pimenta, 2000). Como argumentou Sérgio Buarque de Holanda, não se sabe exatamente quando a "colcha de retalhos" de grupos políticos e indivíduos teria começado a se associar e desejar a emancipação política. "As duas aspirações - a da independência e a da unidade - não nascem juntas e, por longo tempo ainda, não caminham de mãos dadas" (Holanda, citado em Pamplona; Doyle, 2009).

No entanto, se em outras partes do mundo o "nacionalismo tendia a reificar identidades etnonacionalistas", nas Américas seu esforço típico foi abarcar "as identidades étnicas plurais", mesmo mantendo a hierarquização "interna" com negros e índios, ao mesmo tempo que se tornavam sociedades que recebiam grandes levas de imigrantes. Enquanto na Europa, Ásia e África a especificação étnica era forte o suficiente para reivindicar a separação em relação a um "outro", na América ibérica esse outro não era especificamente identificado etnicamente, mas, sim, politicamente (Pamplona; Doyle, 2009, p. 22).

Da vontade de construir a "nação" e/ou fortalecê-la, entre determinados grupos ocorreu o que se pode chamar de "nacionalismo", que despontou em várias localidades da América ibérica. Esse nacionalismo seria caracterizado por um certo sentimento projetivo sobre pessoas, histórias, costumes e coisas, sendo materializado na suposta entidade, a "nação", que deveria ser aparelhada com funções de Estado, formando o "Estado-nação". Era, portanto, também o sentimento/motor ligado 
à ideia da fusão Estado-nação, guiado sobretudo pelas elites (Smith, 2004), engendrando muitas vezes disputas entre "locais" e "nacionais", entre uma pretensão "centralizadora" e outra mais "descentralizadora", comportando vários matizes entre esses polos, e mesmo a separação (ou tentativa) de entidades politicamente vistas como mais "fracas" em relação a outras que procuravam aglutiná-las. De toda forma, as populações que, em tese, deveriam ser homogeneizadas, deveriam ser percebidas como um "povo uno", apesar de suas diferenças étnicas e sociais, mas tendo o seu território como o fundamento da unidade. $\mathrm{O}$ espaço geográfico ocupado nas Américas é que forneceria a base para a reivindicação de sua nacionalidade em construção.

Depois das independências, era contingencial para os novos países estabelecerem limites territoriais como característica das novas soberanias, dos novos países (Foucher, 1986), como era o caso da república boliviana e do Império do Brasil. Antes disso, houve uma série de idas e vindas de autoridades diplomáticas desses países em nome de seus governos centrais (Soares, 1972), mas também havia índios, ribeirinhos, fugitivos criminosos e desertores que, muito provavelmente, não se sentiam nem "bolivianos" nem "brasileiros" nas primeiras décadas de formação dos novos países, transitando entre o departamento de Santa Cruz e a província de Mato Grosso. Era por esses lugares que, mais cedo ou mais tarde, deveria passar a linha limítrofe, demarcando a separação entre os dois países. Essas duas unidades administrativas eram as maiores dos respectivos países, que tinham uma zona de contato e justaposições, e por isso foram várias as correspondências oficiais entre as autoridades locais desses lugares a respeito da faixa geográfica indefinida entre seus representantes, tendo essas pessoas papel não desprezível nos diagnósticos, ações e projeções sobre a zona fronteiriça, influenciando seus governos centrais.

Certamente, esses lugares experimentavam também o que podemos chamar de "fronteira interna". O termo era utilizado, nos séculos XIX e XX, para mostrar até onde a "civilização" havia chegado, e onde não conseguiram estabelecer-se, dentro de um território considerado de um mesmo país (García Jordán, 2001). De maneira não muito diferente, a colonização portuguesa, e depois durante o Império, formavam arquipélagos de povoamentos, com enormes espaços entre uma área e outra (Amado, 1995). De toda forma, era necessário que o território fosse formalmente delimitado e efetivamente demarcado em suas bordas, em um futuro não muito distante, como prerrogativa dos novos Estados nacionais recém-independentes. 
Em Mato Grosso, que tinha a maior extensão territorial de limites a serem definidos, havia muitas áreas não ocupadas por cidades, vilas e povoados, parecendo, como aludimos anteriormente, mais ilhas de ocupação do que faixas de colonização. Não era diferente a principal unidade administrativa boliviana vizinha ao Império, o departamento de Santa Cruz de la Sierra, que possuía poucos núcleos de povoamento, sendo os principais a própria capital, também chamada Santa Cruz, e os focos populacionais constituídos pelas ex-missões de Chiquitos e Mojos, todas consideradas também pelas autoridades como "distantes dos principais centros", localizados nos Andes, como Sucre, Cochabamba e La Paz.

Em meados do século XIX, a população de Santa Cruz de la Sierra era calculada em cerca de 56 mil habitantes (Radding, 2005), diante de uma população total do país estimada em 1,1 milhão. Também com pouca gente, Mato Grosso era calculado pelas suas autoridades com prováveis 55 mil habitantes, diante da estimativa de 6,7 milhões em todo o Império (Sena, 2009). Podemos dizer que entre essas duas, as maiores unidades políticas e administrativas ladeadas internacionalmente, existia uma zona de fronteira caracterizada por uma não separação clara e definida. Ocorria sobretudo a imprecisão, a não presença constante de grupamentos humanos, as distâncias irregulares entre comunidades, a ausência de características físicas dos terrenos que distinguisse consensualmente "um lado" do "outro" nas quais as nacionalidades em construção pudessem se apoiar em uma "natureza" ou mesmo uma "história" inconteste sobre ocupações. Dessa maneira, o termo "zona" ou "região" de fronteira aponta para a fluidez e não fixação efetiva de uma linha divisória entre as partes. Boccara (2005) argumenta que o termo "região" proporciona uma ideia que vai além de uma fronteira separada por uma linha, propondo, então, a justaposição de várias fronteiras e seus arredores, mesmo com os Estados nacionais pretendendo consenso sobre o limite territorial, pois para vários habitantes desse lugar as pretensões das autoridades, descendentes de espanhóis e portugueses, não se confirmavam na prática ${ }^{3}$.

Os Chiquitano demonstram essa forma de ocupação espacial. Esse povo foi formado no período colonial, a partir do fim do século XVII, por aglutinação de várias etnias, inclusive com vários grupos índios que tinham sua territorialidade nas áreas consideradas portuguesas, sob a vontade dos jesuítas de formarem missões nas terras pouco valorizadas

Dessa maneira, é relevada a dinâmica de formações étnicas, incluindo mestiçagens várias, mostrando novas percepções territoriais (Boccara, 2005). 
pela coroa espanhola, mas que era essencial para impedir o avanço de mamelucos e lusitanos. Quando os inacianos foram expulsos em 1767, havia sólidos povoamentos que tinham mesclado várias etnias e culturas, influenciando a religiosidade europeia do lugar e caracterizando-se por serem "chiquitano". O raio de ação desses indígenas incluía terras que hoje são consideradas brasileiras ${ }^{4}$. Do mesmo modo, também no período colonial, escravos fugiam para várias partes, inclusive a que hoje é considerada como Bolívia, tendo relações com outras comunidades, mas precavendo-se da situação hostil dos que queriam reescravizá-los (Lordelo, 2010). Com as independências, essas áreas deveriam ser separadas entre os novos Estados nacionais. As antigas projeções das metrópoles sobre a América não eram fundamento seguro para os novos países que surgiam.

\section{Evadidos e negociações nas "comunidades imaginadas"}

O principal "intercâmbio" entre o que veio a ser Bolívia e o Império do Brasil foi quando as tropas libertadoras já estavam prestes a tomar a maior parte de Santa Cruz, tendo já ocorrido a batalha decisiva de Ayacucho, em que as tropas de Sucre liquidaram as principais forças realistas no antigo vice-reinado do Peru. O governador da província de Chiquitos, Sebastián Ramos, depois de conversas com particulares na então capital de Mato Grosso, Vila Bela, solicitou que enviassem tropa para anexarem as ex-missões ao Brasil. Sem esperar resposta do governo central na corte, que poderia demorar até quatro meses de viagem, algumas dezenas de soldados e um oficial foram mandados para incorporar Chiquitos. Fizeram todo o ritual de posse e se instalaram. Mas logo, tanto o governo de Mato Grosso como D. Pedro I tinham ordenado que os militares se retirassem imediatamente (Calógeras, 1998). Nesse ínterim, o próprio Antônio José de Sucre, braço direito de Bolívia, havia mandado uma carta para D. Pedro e para Vila Bela ameaçando não só retirar os soldados enviados, como ainda invadir e travar guerra contra o Império ${ }^{5}$.

4 Assim, nos dias atuais, apesar de movimentos ruralistas para considerarem-nos bolivianos, e não índios nascidos no Brasil, ainda transitam dos dois lados da fronteira, com parentada e festas religiosas, sobrepondo a fronteira política internacional (Silva, 2008). Desde a saída dos jesuítas, a administração dos povoados ficou com clérigos seculares ou administradores designados pelos governos (Bastos, 1974).

5 O historiador boliviano Ovando Sanz (1986) defende que o Brasil pretendia realmente anexar Chiquitos. Já para o historiador e diplomata brasileiro Villafañe Santos (2002), não havia motivo para $\mathrm{D}$. Pedro concordar em abrir uma nova frente de luta, pois a área estratégica e de maior interesse era no Prata e não as fronteiras de Mato Grosso. 
Quando a tropa deixou Chiquitos, debaixo de uma insurreição chiquitana que também acontecera para referendar mais ainda sua saída, ela foi acompanhada por Sebastián Ramos, seguido por vários indígenas. Grande quantidade de gado, além de preciosidades das igrejas, foram levadas pelo ex-governador (Seckinger, 1985). Ele se arranchou próximo à fazenda nacional Caiçara, perto de Vila Bela, e ao rio Jauru, dentro da zona fronteiriça não definida ainda como limite, o que faria Sebastián Ramos sofrer pressão do governo brasileiro para sair do local, inclusive debaixo da acusação de acoitar escravos.

Foi no momento de criação da Bolívia, forjada em oposição às pretensões de Buenos Aires e de Lima (Roca, 2007), que correu um boato que sacudiu a "boa sociedade" mato-grossense. Segundo a "notícia", os homens de Bolívar, o libertador, invadiria Mato Grosso para alforriar os negros cativos. Os escravos, então, ficaram em euforia e os seus donos se inquietaram exigindo providências enérgicas das autoridades. Até que logo depois correu outra notícia afirmando que a primeira não passava de falsa informação (Seckinger, 1985, p. 18).

Se o líder da emancipação da América do Sul não invadiria o Mato Grosso para libertar os escravos, por outro lado, a senha estava dada: o negro que fugisse para o novo país ao oeste poderia ser liberto. A princípio, teria sido abolida a condição de escravo em território boliviano. Se quilombos e fugas existiam desde quando a escravidão negra chegou a Mato Grosso, junto com o povoamento "branco" no século XVIII, agora poderiam ter um lugar que possivelmente seria mais seguro, debaixo de uma institucionalização criolla que faria parte dos propósitos gerais do liberalismo, inspiradora dos dirigentes dos novos países hispano-americanos nos momentos iniciais. No entanto, é forçoso notar, se houve promessa de extinção da escravidão, inclusive promulgando ou decretando leis, ela não deixou de cessar imediatamente na América do Sul.

Durante os longos anos de guerra pelas independências na América hispânica, havia já promessa de liberdade para os escravos que se engajassem nas lutas. Mesmo a contragosto para muitos dos proprietários, foram numerosos os negros que participaram da linha de frente. Como mostra Andrews (2007), se sobrevivessem (pois a mortandade era grande), poderiam continuar com a condição de libertos caso não houvessem incorrido em nenhuma infração disciplinar. Mesmo assim, houve casos de reescravização após o serviço militar. De toda forma, mães de escravos procuravam ativamente os serviços de alistamento na esperança de verem seus filhos livres. Com leis de 
ventre-livre, foi dado um aceno para o fim da escravidão no início das guerras de independência, sendo promulgadas em lugares como Chile e Argentina, onde ocorreram essas primeiras iniciativas. Depois, nos anos finais do conflito, foram promulgadas na Colômbia, Equador, Peru e Venezuela. Juntamente às leis sobre os nascidos de escravas, também houve as que impediam o tráfico negreiro, o que, conjugado com os nascimentos de livres, previa o fim da escravidão nos novos países recém-independentes (Andrews, 2007, p. 92-95). Mas as coisas não ocorreram tão bem quanto projetado pelos ideários emancipacionistas.

Embora, desde 1817, Bolívar proclamasse que a abolição deveria ser universal e um dos propósitos das guerras de independência, desde o início essas leis causaram controvérsias. Os dois "direitos naturais" mais propalados, o da "propriedade" e o da "liberdade", se chocavam nos discursos de viés ilustrado no processo de independência e nas décadas subsequentes (Secreto, 2011). As reivindicações sobre a propriedade acabaram fazendo com que a escravidão nos novos países persistisse por mais algumas décadas. $\mathrm{O}$ nascido de escrava deveria esperar a "maioridade", condição para ganhar a alforria. Quando se aproximou a época em que os primeiros libertos teriam entre 18 e 21 anos, em vários lugares mudaram a condição para ser considerada a idade maior. Assim, no Peru, a idade adulta passou a ser de 50 anos! Colômbia, Uruguai e Venezuela colocaram como limite 25 anos. Por outro lado, Argentina e Uruguai abriram novamente o tráfico de escravos na década de 1830. Ou seja, procuraram de diversas maneiras protelar o trabalho escravo nos novos países. Nos locais em que, no tempo de colônia, o trabalho escravo era considerado vital para a economia, foi onde houve mais resistência dos senhores em relação ao que consideravam sua propriedade (Andrews, 2007, p. 123).

No caso da Bolívia, especificamente, Caldeira (2009) considera que o país foi o primeiro da América do Sul a adotar o seu território como "solo livre" em relação à escravidão. Não somente ninguém poderia ser escravo, como as pessoas que lá estivessem ou entrassem não poderiam ser enviadas para ser cativas no exterior, pois assim contribuiria para a "reescravização" de seres humanos. Continuando o autor, as cartas constitucionais de 1826, 1831, 1834, 1839, assim como o código penal de 1836 , reiteravam sucessivamente sobre a extradição ou repatriação dos fugitivos que entrassem na Bolívia, considerando assim o país como avesso ao trabalho escravo. Isso fazia com que as autoridades bolivianas se desentendessem com o Império do Brasil, rejeitando os pedidos dos diplomatas brasileiros referentes à extradição dos negros fugidos que 
cruzavam a fronteira. Por fim, antes do primeiro tratado entre a Bolívia e Brasil, em 1867, já havia recomendação para que os representantes do Império não colocassem mais na pauta de diálogo a devolução dos evadidos (Caldeira, 2009, p. 249-272).

O texto de Caldeira apoiou-se em documentação diplomática, do Ministério das Relações Exteriores. No entanto, com base em outras fontes, como a documentação existente em Mato Grosso e em Santa Cruz de la Sierra, podemos dizer que não somente a escravidão não fora totalmente extinta com a criação da Bolívia, como, principalmente, o solo boliviano não era garantia de asilo seguro e liberdade para os escravos fugidos do Brasil. Talvez a reiteração da proibição da escravidão e a declaração de "solo livre" se devessem justamente porque, na prática, a forma de trabalho compulsória de negros ainda acontecesse, mesmo longe de ser predominante, sem competir com as diversas modalidades de trabalho indígena. Também podemos dizer que era uma maneira de a Bolívia se apresentar ao mundo depois das guerras de independência.

Nesse sentido, um documento sem data, mas em fundo do período republicano, expressa a vontade de um senhor, Juan José Soría, em reaver seu cativo que fugira para o sul do departamento de Santa Cruz. A carta é endereçada ao prefeito da capital do departamento:

(...) fue hace el espacio de ocho años compré para mi esclavo un negro llamado Antonio Rivero en cantidad de 50\$ dinero efectivo a D. Antonio Oliva que era su amo; Eso esclavo a los seis días que fue comprado se fugó hasta el día, sin aprovechar (...) de él más pequeño servicio que tanto he interesado, y sabiendo positivo que esta se halla en el lugar de Piraimiri [...] de Valegrande ${ }^{6}$.

Outro documento, agora datado da metade do século XIX, mostra o mesmo Juan José Soría disponibilizando seu escravo para obras de construção de uma catedral. A relação entre as autoridades e o proprietário são reveladoras em relação à anuência da escravidão: "Aceptouse en cuanto há lugar la oferta que hace el presentante Ciudadano Juan José Soría de los servicios que ofrece de su esclavo Antonio Ribas", para que trabalhe "en la obra de la Santa Iglesia Catedral de esta ciudad hasta su conclusión". No mesmo texto pedia-se para que o chefe da polícia fosse comunicado e ficasse ciente do zelo "patriotico" e "filantropico" desse senhor".

6 Museo de Historia y Archivo Histórico de Santa Cruz (MHAHSC). Juan José de Soría. Código 1/32-20, legajo 67, fondo prefectural.

7 MHAHSC. Prefectura del Departamento de Santa Cruz, 19 de setembro de 1853. Código 1/32-20, legajo 67 , fondo prefectural. 
Secreto (2011) mostra que na constituição boliviana de 1826 foi sancionada a liberdade de escravos, enquanto outra lei, do mesmo ano, preconizava que o escravo deveria "indenizar seu proprietário com o valor pelo qual tinha sido comprado". Ou seja, era uma "compra" da liberdade, não uma "abolição" da escravidão. Depois, a Constituição de 1831 revogou a lei que tornava livres os filhos de escravas que nascessem a partir de janeiro de 1813, semelhante aos casos de lugares que vimos anteriormente, passando para o dia 6 de agosto de 1825 , data comemorativa da independência boliviana. Ao contrário de Caldeira, para a autora foi somente em 1851, depois de aprovada na nova Constituição, que se efetuou a abolição, quando estava expresso que "Todo homem nasce livre na Bolívia, todo homem recupera sua liberdade ao pisar o seu território. A escravidão não existe nem pode existir" (Secreto, 2011, p. 145). No entanto, o caso do escravo de Soría, que emprestou seu cativo por "filantropia" para as obras de uma igreja, era registrado dois anos depois da Carta que aboliria (novamente, e última vez) a escravidão, inclusive não somente com concordância das autoridades locais, como vimos, mas também fazendo o "proprietário" ser qualificado perante os cruzenhos.

De toda forma, na Bolívia a escravidão de descendentes de africanos não fazia parte do cotidiano de maneira tão contundente quanto no Brasil. Assim, se o fim da escravidão foi postergado nos países da América do Sul de colonização hispânica, no Império do Brasil a manutenção do regime escravocrata foi um dos principais fatores de união das diversas elites locais. Sob a pressão da Inglaterra contra o tráfico negreiro, na década de 1830 foi editada uma lei que proibia o tráfico de escravos para o território brasileiro. No entanto, os proprietários de terra continuavam escravizando pessoas tidas então como livres, que no Brasil continuavam a chegar, na esperança de que o Estado lhes garantisse a nova "propriedade". O país chegou a separar quantias monetárias para uma possível guerra contra a Inglaterra. Por fim, debaixo de pressão externa, o tráfico foi extinto em 1850, conjugado com uma lei de terras, querendo impulsionar o mercado, pretendendo reservar mão de obra para a agricultura, a base da arrecadação e sustento do Império, enquanto os dirigentes sonhavam com a vinda de imigrantes não africanos (Parron, 2011).

Portanto, sendo caro aos proprietários brasileiros seus cativos africanos ou descendentes, nada pior para os que possuíam escravos do que ter um vizinho que fazia alusão a possuir um território de "liberdade". Era com base nesse pressuposto que oficialmente a Bolívia argumentava 
não entregar negros fugidos, já nas primeiras décadas de existência, apesar de certa confusão de leis sobre o cativeiro internamente.

Em Mato Grosso, se desde o período colonial os cativos procuravam a região de domínio espanhol para empreenderem fuga, depois das independências, o país vizinho podia ser vislumbrado como um lugar de liberdade instituída, mesmo que na prática isso não acontecesse, como vimos. De toda forma, a indefinida zona de fronteira era a primeira região por onde esses escravos passariam, podendo, inclusive, lá permanecer. As autoridades mato-grossenses e os proprietários não poderiam deixar barato. As fugas de escravos, então, passaram a ser parte das reivindicações diplomáticas. Os presidentes de província escreviam frequentemente para os homens públicos do departamento de Santa Cruz de la Sierra, como para a governadoria de Chiquitos (unidade menor, vinculada ao departamento), solicitando a devolução dos cativos evadidos. Os dirigentes de Mato Grosso também se correspondiam com os diplomatas brasileiros em missão na América hispânica, em especial com os que estivessem ou fossem se dirigir à Bolívia, reforçando os pedidos de extradição e comunicando a situação da região fronteiriça.

Em 1843, o vice-presidente de Mato Grosso Manuel Alves Ribeiro escrevia para o governador solicitando a "entrega" de vários escravos que estavam "asilados por Sebastián Ramos, súdito boliviano"8. Como vimos, Sebastián Ramos, ex-governador de Chiquitos, havia migrado para a zona fronteiriça. Lá se afazendou. Depois, na década de 1830, tornou-se um estorvo para autoridades brasileiras. Seu arranchamento, além de acolher escravos fugidos, e outras pessoas consideradas criminosas pelos brasileiros, estava em lugar litigioso, perto do marco do Jauru. Foram tantas pressões sobre o ex-governador de Chiquitos que ele acabou se retirando momentaneamente da zona fronteiriça, mas retornou, para onde hoje é San Matías, perto de um destacamento brasileiro, proclamando-se "guardião" das fronteiras da Bolívia, mais de trinta anos depois de ter saído da governadoria de Chiquitos. Assim, Ramos, que antes não era nem "boliviano", nem "brasileiro adotivo" nos primeiros tempos de independência, passou a assumir posturas nacionalistas, tal como as descritas anteriormente por Smith, tendo como oponente e incentivador de sua posição os atos do Império, pois

Arquivo Público de Mato Grosso (APMT). Registro de Correspondência entre a Província e a Bolívia (RCPB). Manuel Alves Ribeiro para chefe de da Província de Chiquitos. Cuiabá, 2 de setembro de 1843. 
lutava constantemente contra as "usurpaciones de los brasileros del territorio Boliviano"9.

Entre vários lugares em que havia controvérsia sobre se era território "brasileiro" ou "boliviano", existia um chamado Guarajus, na região amazônica, no vale Guaporé. Esse lugar suscitou divergências sobre sua posse quando bolivianos foram até lá garimpar. Mas outro problema com que as autoridades brasileiras se depararam foi a descoberta de que o lugar servia de passagem para fuga de escravos. Logo enviaram tropa para o lugar. Não seria devido a uma suposta guerra por território, assunto que pessoas incautas falavam na zona fronteiriça vez por outra, pois, segundo o comandante do destacamento militar da Cidade de Mato Grosso, seria contrário ao "Direito das Gentes" que deveria prevalecer entre os dois países, mas, sim, por representar uma "crescente rota" de evasão, havendo então a necessidade de "privar as fugas de escravos dos proprietários" da província, que poderiam ser "infalivelmente contínuas", trazendo grandes prejuízos aos particulares ${ }^{10}$.

Se através dos documentos diplomáticos, como os expostos por Newman Caldeira, a Bolívia se apresentava como "solo livre" da escravidão, negando oficialmente a possibilidade de extraditar escravos, nem sempre as autoridades bolivianas de fronteira agiram na coibição de deportação dos fugitivos para o Império, pelo menos eficazmente, como veremos ${ }^{11}$.

Em 1837, o presidente de província enviou uma carta para Santa Cruz de la Sierra especificando o valor de "indenização", $12 \$ 8000$ por negro que estivesse no departamento, e fosse entregue em um ponto com guarnição brasileira, na zona de fronteira ${ }^{12}$. Uma maneira mais eficaz foi quando um comissionado brasileiro, Mariano Ribeiro da Silva Apinajé, provavelmente um mateiro da etnia de seu nome, foi mandado para o

9 ABNB. MI. t. 174. n. 17, Sebastián Ramos para Ministro da Guerra. San Matías, 6 de agosto de 1861.

10 Arquivo Público de Mato Grosso (APMT). Caixa 1843 D. Documentos avulsos. Vicente Rebelo Leite Pereira para Presidente de Província, Cidade de Mato Grosso, 18 de novembro de 1843 .

11 As autoridades e proprietários brasileiros procuraram várias estratégias para impedir a diminuição do plantel de trabalhadores forçados - tal como eles acusavam que estava acontecendo na província -, como a instalação de destacamentos por onde poderia ser saída de negros. Foi dessa maneira, por exemplo, que negaram a passagem de Oliden pelos "campos do marco do Jauru", alegando que o trânsito para a Bolívia por aquela área estava obstruído também pelas fugas que por ali ocorriam (APMT. RCPB. Pimenta Bueno, Pimenta Bueno Manuel para Oliden, Governador de Otuquis. Cuiabá, 10 de março de 1838), além do fato de que o governo imperial, inegavelmente, percebia aquela zona sensível aos reclames de posse bolivianos.

12 APMT. RCPB. Pimenta Bueno para Ribeiro da Silva. Cuiabá, 10 de junho de 1837. 
país vizinho requerer, presencialmente, ao prefeito do departamento de Santa Cruz, a apreensão e pagamento de indenizações (o que na verdade era o termo usado para pagar recompensas) referentes à entrega de escravos brasileiros. O presidente de Mato Grosso acrescentava ainda que os bolivianos poderiam usar os negros momentaneamente em serviços no seu país, como forma de compensação. Ao mesmo tempo, em linguagem diplomática, dizia que seria contra todos os direitos que soldados brasileiros entrassem em território boliviano, ou que o comissionado, que estava em Santa Cruz naquela ocasião, reunisse gente armada para reaver os pertences brasileiros. Por isso, solicitava a "bondade de mandá-los entregar" na "fronteira sob a conveniente guarda"13.

Mesmo não havendo resposta das autoridades bolivianas a esses ofícios, essa tática tinha demonstrado resultados. O futuro marquês de São Vicente, Pimenta Bueno, então escrevia para o representante brasileiro na capital da Bolívia comunicando que "escravos refugiados em Santa Cruz têm sido restituídos ao comissionado Mariano Apinajé”, além de outros, que por Moxos foram entregues de volta ao Império, reentrando pelo forte Príncipe da Beira ${ }^{14}$. Ou seja, mesmo sendo negado oficialmente tal procedimento pelos governantes da capital Chuquisaca (Cidade de Sucre), muito provavelmente houve colaboração das autoridades das províncias de fronteira desse país para a reescravização dos fugitivos.

Quando as províncias do oriente boliviano passaram a seguir mais estreitamente as determinações do governo central, negando a extradição de negros fugidos, o presidente de Mato Grosso logo fez protestos, argumentando que em "várias datas" foram "expedidas ordens para que eles sejam entregues" aos brasileiros. Por isso, esperava que não se negassem à continuidade "da entrega de tais escravos que são propriedade brasileira"15.

Diante das negativas do país vizinho, proprietários passaram a organizar mais expedições para áreas tidas como bolivianas em busca dos fugitivos. O prefeito de Santa Cruz fez uma representação contra esses agrupamentos armados, pois feria incisivamente a soberania

13 APMT. RCPB. Pimenta Bueno para representante brasileiro em Chuquisaca, Ponte Ribeiro, Cuiabá, 11 de maio de 1838.

14 APMT. RCPB. Pimenta Bueno para Ponte Ribeiro, Encarregado de Negócios do Brasil na República de Bolívia. Cuiabá, 11 de maio de 1838.

15 APMT. RCPB. p. 156. José da Silva Guimarães para D. João Baca, Governador e Chefe Supremo da Província de Chiquitos. Cuiabá, 11 de outubro de 1841. 
boliviana. Seria um abuso homens portando armas entrarem em seu território. $\mathrm{O}$ então presidente, Moreira Freire, argumentava que não sabia de tais abusos, mas "talvez tenha havido algum excesso de algum particular, mas de pouca monta", o que não significava que o governo não tomasse constantes providências em adotar medidas policiais na "nossa fronteira, a fim de vedar a fuga de escravos e garantir esta propriedade dos súditos brasileiros, princípios estes que são incontestáveis pelo Direito das Gentes e que esse governo desconhece pela proteção que dá aos referidos escravos". Lembrando que para os bolivianos seria justamente o fluido "Direito das Gentes" que impediria reduzir uma pessoa à escravidão. Mas o território, ainda que não delimitado e definido em suas raias, deveria ser respeitado por "práticas costumeiras", que era a base do Direito das Gentes, tão mencionado pelas elites políticas, mas não estipulado em sua formulação estrita para aplicação universal (Chiaramonte, 2010).

Por fim, diante de várias queixas tanto do governo mato-grossense como do central, além dos particulares, o presidente da província brasileira, que tinha a maior zona de fronteira com a Bolívia, acabou por escrever para o representante do Brasil em Chuquisaca que não era possível tratar localmente, ou seja, entre as províncias fronteiriças, sobre as fugas de escravos. As autoridades das raias não colaborariam mais, sendo "assunto tão complicado" que somente poderia ser "entabulado" e decidido "por meio da diplomacia"16. Quando houve o primeiro tratado sobre limites entre o Império e a Bolívia, não havia mais espaço para reivindicar devoluções de escravos em meio ao que acontecia no Ocidente. O Brasil era um dos últimos países a manter oficialmente a instituição escravagista, tendo já sido direcionado o seu fim, em algum momento próximo, para desgosto dos proprietários que atrelavam sua produção e a "prosperidade" da "nação" à manutenção do cativeiro.

$* * *$

Certamente, os que empreendiam fuga de seus senhores não se viam como parte da "comunidade imaginada" no período de construção do Brasil. Se a nação moderna na América deveria englobar múltiplas etnias, muitos indivíduos marcados justamente pela sua cor de pele, ascendência cultural e estatuto jurídico social, procuravam novas

16 APMT. RCPB. Zeferino Pimentel Moreira Freire para João da Costa Rego Monteiro, Encarregado de Negócios do Brasil na República de Bolívia. Cuiabá, 17 de junho de 1844. 
perspectivas de vida no país vizinho ou na zona de fronteira. Esses lugares, por não ter uma concordância entre as autoridades dos países onde começaria um território e terminaria outro, também por não serem uma área suficientemente vigiada ou mesmo conhecida, eram locais que poderiam oferecer uma oportunidade de nova vida para os que fugiam, sem se perceberem como parte integrante ou fundamental de uma "comunidade" que não lhes interessava.

Por outro lado, se desde as guerras de independência, e a consequente criação da Bolívia, o fim da escravidão era uma proposta totalmente congruente com os propósitos libertadores. Mas não só a escravidão permaneceu, mesmo que bastante diminuta, como, inclusive, o "imposto indígena", retornou - depois de extinto por alguns anos em nome da "cidadania nacional" -, para tentar municiar os cofres do combalido país que procurava se construir, dividindo novamente a população em "estamentos". Ao mesmo tempo, a Bolívia apresentava-se como território sem escravidão negra nas conversas diplomáticas, fruto das ideias liberais, de acordo com o que podemos apreender de Caldeira. No entanto, a fuga para lá não significava franca liberdade. Não apenas os senhores de escravos da província vizinha, Mato Grosso, se organizaram para não perder seus braços cativos, como alguns bolivianos que conseguiam capturá-los se interessavam pelas recompensas.

Como característica dos novos países que se formavam no século XIX, as fronteiras deveriam ser definidas entre eles. Se desde as primeiras décadas de independência a Bolívia esperava usar a ideia de ser um lugar com "solo livre" (o que incitaria a fuga de escravos) como trunfo em uma estratégia de negociação com o Império do Brasil, no momento em que acabou sendo feito o acordo, já no fim da década de 1860, não cabia mais tal tipo de barganha, pois já era apontado o fim da escravidão no principal país escravagista da América. Antes do acordo territorial, a devolução de escravos deixou de ser pauta elencada pelas autoridades brasileiras nas conversas diplomáticas, como era até a metade do século XIX. Interessante notar, as autoridades de Mato Grosso mantinham diálogos com os oficiais brasileiros em missão, colaborando nas proposições e reivindicações, pois percebiam de perto a situação fronteiriça, inclusive o desconhecimento de vastas áreas e a pressão dos proprietários de escravos.

$\mathrm{O}$ destino dos cativos que escaparam e se instalaram na zona de fronteira, ou entraram no que hoje é Bolívia, ainda não é conhecido. Certamente era alentador imaginar que haveria uma terra em que pudessem viver sem perseguição institucional. Mas, muito provavelmente, logo 
saberiam que particulares, tanto de um lado da fronteira como de outro, poderiam trabalhar para reescravizá-los. Nesse sentido, eram a prova viva das clivagens e obstáculos dos projetos nacionais formados com o fim do chamado Antigo Regime, ou seja, da formação das nações modernas.

\section{Referências}

AMADO, Janaina. Construindo mitos: a conquista do oeste no Brasil e nos EUA. In: PIMENTEL, Sidney Valadares; AMADO, Janaina (Org.). Passando dos limites. Goiânia: Ed. da UFG, 1995.

ANDERSON, Benedict. Introdução. In: BALAKRISHNAN, Gopal. Um mapa da questão nacional. Rio de Janeiro: Contraponto, 2000.

ANDERSON, Benedict. Comunidades imaginadas. São Paulo: Companhia das Letras, 2008.

ANDREWS, George Reid. América afro-latina - 1800-2000. São Carlos: EdUSCAR, 2007.

BASTOS, Uacury Ribeiro de Assis. Os jesuitas e seus sucessores - Moxos e Chiquitos (1767-1830). São Paulo: FFLCH-USP, 1974.

BOCCARA, Guillaume. Génesis y estructura de los complejos fronterizos euroindígenas. Repensando los márgenes americanos a partir (y más allá) de la Obra de Nathan Wachtel. In: Memoria Americana, Buenos Aires, n. 13, p. 21-52, 2005.

CALDEIRA, Newman di Carlo. Brasil e Bolívia: fugas internacionais de escravos, navegação fluvial e ajustes de fronteira (1822-1867). Fronteiras, Dourados, v. 11, n. 19, p. 249-272, jan./jun. 2009.

CALÓGERAS, J. Pandiá. A politica exterior do Império. Edição fac-similar. Brasília: Senado Federal, 1998.

CHIARAMONTE, José Carlos. Nación y estado en Iberoamérica - El lenguaje político en tiempos de las independencias. Buenos Aires: Editorial Sudamericana, 2004.

CHIARAMONTE, José Carlos. Fundamentos intelectuales y politicos de las independencias: notas para una nueva historia intelectual de Iberoamérica. Buenos Aires: Teseo, 2010.

FOUCHER, Michel. L'invention des frontières. Paris: F.E.D.N., 1986.

GARCÍA JORDÁN, Pilar. Cruz y arado, fusiles y discursos - La construcción de los Orientes en el Perú y Bolivia 1820-1940. Lima: Editora IFEA/IEP, 2001.

GUERRA, François-Xavier. A nação moderna: nova legitimidade e velhas identidades. In: JANCSÓ, István (Org.). Brasil: formação do Estado e da Nação. São Paulo: Hucitec/ Fapesp/Unijuí, 2003.

JANCSÓ, István, PIMENTA, João Paulo. Peças de um mosaico (apontamentos para o estudo da emergência da identidade nacional brasileira). In: MOTA, Carlos Guilherme (Org). Viagem incompleta. A experiência brasileira 1500-2000. São Paulo: Senac, 2000.

KIDD, Colin.Identity before Identities: Ethnicity, Nationalism, and the Historian. In: RUDOLPH, Julia (Ed). History and Nation. Lewinsburg: Bucknell University Press, 2006. 
LORDELO, Monique C. S. Escravos negros na fronteira oeste da capitania de Mato Grosso: fugas e capturas (1748-1796). In: Anuario de Estudios Bolivianos, Archivísticos y Bibliográficos, v. n. 16, p. 171-196, 2010.

OVANDO SANZ, Jorge Alejandro. La invasión brasileña a Bolivia en 1825. La Paz: Libreria Editorial "Juventud", 1986.

PAMPLONA, Marco A.; DOYLE, Don H. Nação e nacionalismo no novo mundo - A formação de Estados-nação no século XIX. Rio de Janeiro/São Paulo: Record, 2009.

PARRON, Tamis. A política da escravidão no Império do Brasil - 1826-1865. Rio de Janeiro: Civilização Brasileira, 2011.

RADDING, Cynthia. Paisajes de poder e identidad. Fronteras imperiales en el desierto de Sonora y bosques de la Amazonía. Sucre: FCBCB - Archivo y Biblioteca Nacionales de Bolivia, 2005.

ROCA, José Luis. Ni con Lima ni con Buenos Aires: La formación de un Estado nacional en Charcas. La Paz, IFEA/Plural editores, 2007.

SANTOS, Luís Cláudio Villafañe Gomes. O Império e as repúblicas do Pacifico - As relações do Brasil com Chile, Bolívia, Peru, Equador e Colômbia (1822-1889). Curitiba: UFPR, 2002.

SECKINGER, Ron L. La cuestión de chiquitos: una breve crisis en las relaciones boliviano-brasileñas. Revista de la Universidad Gabriel René Moreno, Santa Cruz de la Sierra, n. 39-40, 1985.

SECRETO, María Verónica. Soltando-se das mãos: liberdades dos escravos na América Espanhola. In: AZEVEDO, Cecília: RAMINELLI, Ronald. História das Américas novas perspectivas. Rio de Janeiro: Ed. FGV/EdUFF, 2011.

SENA, Ernesto Cerveira de. Entre anarquizadores e pessoas de costumes - a dinâmica política nas fronteiras do Império - Mato Grosso (1834-1870). Cuiabá: Carlini \& Caniato/EdUFMT, 2009.

SILVA, Joana Fernandes. Identidades e conflitos na fronteira: poderes locais e os Chiquitanos. Memoria Americana, Buenos Aires, v. 16, n. 2, p. 119-148, 2008.

SMITH, Antony D. Nacionalismo, Madri: Alianza Editorial, 2004.

SOARES, Teixeira. História da formação das fronteiras do Brasil. 2. ed. Rio de Janeiro: Conselho Federal de Cultura, 1972. 